\title{
Proksymalna resekcja subtotalna żołądka metodą DTR w leczeniu wczesnego raka połączenia przełykowo-żołądkowego — SIEWERT III
}

\author{
Grzegorz Celban, Paweł Pius, Piotr Januszewski
}

Proksymalna resekcja żołądka z powodu raka jest rzadko wykonywaną procedurą. Jej wykonanie jest zalecane w przypadku raka wczesnego 1/3 bliższej części żołądka przy niemożności wykonania leczenia endoskopowego lub nieradykalności takiego leczenia. Spośród sposobów rekonstrukcji przewodu pokarmowego nie istnieje dotychczas metoda wyraźnie korzystniejsza od pozostałych. Zaletą metody DTR (double tract reconstruction) jest zachowanie fizjologicznego pasażu pokarmu przez dwunastnicę, zbliżone do fizjologicznego współdziałanie hormonów żołądkowo-jelitowych i możliwość endoskopowej kontroli kikuta żołądka, dwunastnicy i dróg żółciowych. W poniższej pracy przedstawiono zastosowanie tej metody w leczeniu raka w polipie połączenia przełykowo-żołądkowego.

\section{Antrum preserving double tract reconstruction following proximal gastrectomy for Siewert type III early adenocarcinoma of the oesophagogastric junction (AEG) - case report}

Proximal gastrectomy is hardly ever used, nevertheless it can be recommended for early lesions of the upper-third of the stomach. In cases when endoscopic treatment is impossible or the criteria for radical endoscopic therapy are not fulfilled, the patient should receive surgery. There are methods available for digestive tract reconstruction but none are likely to provide a favourable outcome. However, the antrum preserving double tract method is a reasonable approach since it can maintain a smooth transfer of bulky foodstuffs through the duodenal route. We report an application of this method in the treatment of early AEG cancer.

Słowa kluczowe: rak wczesny żołądka, proksymalna resekcja żołądka, metoda DTR

Key words: early gastric cancer, proximal gastrectomy, double tract reconstruction

\section{Wstęp}

Rak wczesny żołądka jest stwierdzany w 5-25\% wszystkich przypadków raka żołądka. W niektórych przypadkach możliwe jest skuteczne leczenie endoskopowe. Leczenie to może polegać na radykalnej onkologicznie endoskopowej resekcji śluzówki (EMR - endoscopic mucosal resection) lub endoskopowej dyssekcji podśluzówkowej (ESD — endoscopic submucosal dissection). $U$ pozostałych chorych radykalne leczenie zapewnia chirurgia klasyczna, laparoskopowa lub robotowa. W przypadku nieradykalnej onkologicznie polipektomii raka w polipie żołądka leczeniem z wyboru pozostaje leczenie chirurgiczne. $W$ omawianej pracy opi- sano zabieg proksymalnej resekcji żołądka metodą DTR jako dobrej opcji w porównaniu z proksymalną resekcją żołądka ze wstawką jelitową (np. sposobem Longmire'a) lub całkowitą resekcją żołądka.

\section{Opis przypadku}

36-letnia chora przejawiająca niespecyficzne dolegliwości bólowe nadbrzusza, dotychczas zdrowa, przebyła 22 października 2015 r. zabieg endoskopowej polipektomii żołądka. Półuszypułowany polip o średnicy głowy $1,5 \mathrm{~cm}$ zlokalizowany $2,5 \mathrm{~cm}$ pod linią Z został usunięty metodą kęsową i odzyskany w 3 fragmentach do badania histopa- 


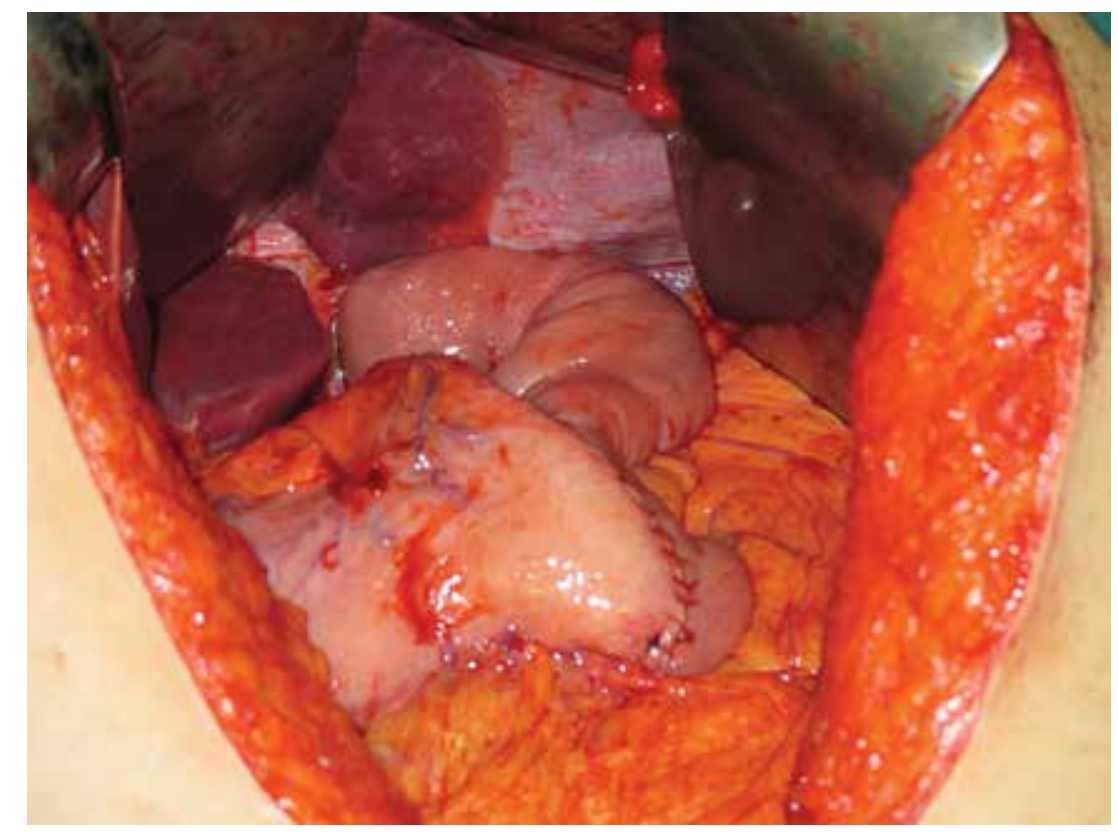

Rycina 1. Obraz śródoperacyjny zespolenia przełykowo-czczego i żołądkowo-czczego metodą DTR

tologicznego. Badanie wykazało naciek raka gruczołowego G-2 we wszystkich trzech fragmentach polipa. Podczas kontrolnej panendoskopii wykonanej 16 listopada 2015 r. nie odnaleziono blizny po polipektomii. Badania obrazowe nie wykazały ani guza, ani rozsiewu nowotworowego. Wobec braku kryteriów doszczętnej onkologicznie polipektomii chorą zakwalifikowano do leczenia operacyjnego. 30 listopada 2015 r. wykonano pierwszą w naszym ośrodku subtotalną resekcję proksymalną żołądka metodą DTR, opierając się na dobrych doświadczeniach ośrodków japońskich. Po usunięciu 2/3 żołądka w trakcie 4-godzinnego zabiegu wykonano staplerowe typowe zespolenie przełykowo-czcze koniec do boku na górnej pętli Roux. Następnie wykonano dwa ręczne zespolenia koniec do boku: żołądkowo-czcze i czczo-czcze $z$ dolną pętlą Roux. Zabieg uzupełniono o pyloroplastykę sposobem Heineke-Mikulicza i limfadenektomię D1+. Obraz śródoperacyjny przedstawiono na rycinie 1.

Wdrożono żywienie dojelitowe przez sondę dojelitową w pierwszej dobie po zabiegu i pełne żywienie doustne od piątej doby po zabiegu. Nie stwierdzono poważnych powikłań pooperacyjnych, natomiast obserwowano wzdęcie nadbrzusza utrzymujące się do drugiej doby po zabiegu, w której wystąpił powrót żywej perystaltyki i pierwsze wiatry. W badaniu histopatologicznym preparatu operacyjnego nie stwierdzono ognisk nowotworu ani w obrębie żołądka, ani węzłów chłonnych (liczba odnalezionych, usuniętych węzłów chłonnych: 29). Badanie kontrolne wykonane 1 i 2 miesiące po zabiegu wykazało niezmienioną masę ciała, dobrą jakość życia i prawidłowe wyniki badań laboratoryjnych.

\section{Omówienie}

Całkowita resekcja żołądka u chorych na raka zlokalizowanego w proksymalnej 1/3 żołądka jest nadal standardowym postępowaniem chirurgicznym. Niesie ona jednak szereg niekorzystnych następstw metabolicznych (zaburzenia wchłaniania, anemia, osteoporoza) i gorszą jakość życia (spadek masy ciała, brak apetytu, niemożność spożywania posiłków o normalnej objętości, refluks jelitowo-przełykowy, zespoły poresekcyjne). Zgodnie z polskimi ustaleniami [1] rozpoznanie raka wczesnego zlokalizowanego w okolicy podwpustowej i dnie żołądka daje możliwość proksymalnej resekcji subtotalnej. Jednak zdaniem wielu autorów zabieg ten obciążony jest większym ryzykiem nieszczelności zespoleń, wyższą śmiertelnością pooperacyjną, a w przypadku raka zaawansowanego - gorszymi wynikami odległymi w porównaniu z resekcją całkowitą [2]. Dyskusyjnajest kwestia redukcji zaburzeń wchłaniania czy refluksowego zapalenia przełyku po proksymalnej resekcji subtotalnej żołądka. Sposób rekonstrukcji przewodu pokarmowego może wpływać na częstość ww. powikłań i jakość życia. Do dyspozycji chirurga pozostają metody z użyciem wstawki jelitowej, zbiornika jelitowego, zespolenia przełykowo-żołądkowego czy DTR. Przegląd bieżącego piśmiennictwa wskazuje, że większość tych zabiegów wykonywana jest obecnie laparoskopowo. Metoda DTR z zaoszczędzeniem antrum została opisana po raz pierwszy przez Aikou z Japonii w 1988 roku jako sposób resekcji proksymalnej żołądka, zachowującej zbliżony do fizjologicznego profil wydzielania gastryny i fizjologiczny pasaż pokarmu [3]. Schemat omawianego zabiegu ilustruje rycina 2 . 


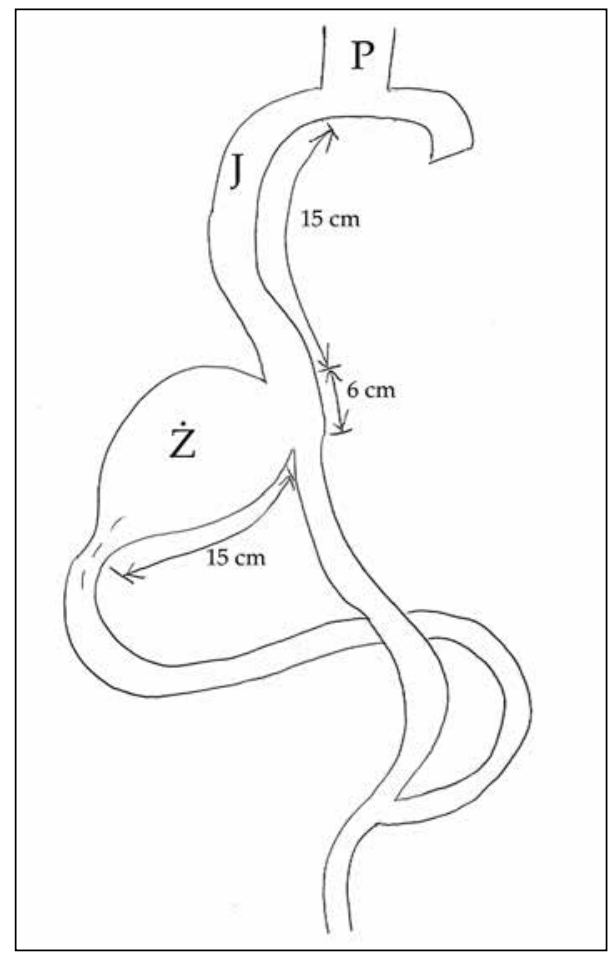

Rycina 2. Schemat proksymalnej rekonstrukcji metodą DTR ( $\mathrm{P}$ - przełyk, Ż - kikut żołądka, J - jelito czcze)

Według Nakamury [4] bezpośrednie zespolenie przełykowo-żołądkowe skutkuje najwyższym odsetkiem refluksowego zapalenia przełyku. Pozostałe metody rekonstrukcji nie różnią się zasadniczo pod względem odsetka powikłań chirurgicznych, wyników odległych, oceny endoskopowej czy jakości życia, ale zalecane są prospektywne, wieloośrodkowe badania. Według najnowszych doniesień autorów azjatyckich resekcja proksymalna żołądka metodą DTR daje szereg korzyści metabolicznych, mniejszy odsetek refluksowego zapalenia przełyku, biegunki, anemii czy spadku masy ciała, a wyniki odległe (przeżycia całkowite, przeżycia wolne od choroby) nie różnią się w porównaniu z resekcją całkowitą metodą Roux-en-Y [5-7]. Rozpoczyna się właśnie koreańskie randomizowane, wieloośrodkowe badanie kliniczne dotyczące wyboru strategii postępowania chirurgicznego u chorych na wczesnego raka proksymalnej części żołądka [6]. Niektóre badania wskazują na korzystny profil insulinemii i hiperglikemii pooperacyjnej po DTR w porównaniu z zabiegiem z użyciem wstawki jelitowej - autorzy zalecają jego wykonywanie u cukrzyków [8].Zdaniem jednych autorów odsetek refluksowego zapalenia przełyku po DTR wynosi zaledwie kilka procent [9]. Według innych autorów wzrasta on nieznamiennie statystycznie w porównaniu z chorymi przed operacją, natomiast wyraźnie wzrasta szybkość opróżniania kikuta żołądkowego, tym bardziej że pyloroplastyka jest zalecaną składową zabiegu [10-12] .
Istotną kwestią jest wykonanie szerokiego - minimum $6 \mathrm{~cm}$ - zespolenia żołądkowo-czczego w trakcie zabiegu DTR. Wykazano bowiem, że pooperacyjny spadek masy ciała i ilość przyjmowanego posiłku zależą od objętości pozostawionego żołądka i łatwości przesuwania się pokarmu w obrębie szeroko wykonanych zespoleń [10].

Zaletą omawianego zabiegu jest możliwośćocenyi ewentualnego leczenia endoskopowego zmian patologicznych kikuta żołądkowego, dwunastnicy i dróg żółciowych [13]. Na dostępność endoskopową do dwunastnicy i dróg żółciowych oraz fizjologiczny pasaż pokarmu zwracają uwagę również polscy autorzy z Białegostoku, którzy stosują z powodzeniem metodę DTR po całkowitej resekcji żołądka [14]. Ponadto zachowanie fizjologicznego pasażu pokarmu przez dwunastnicę po gastrektomii zdaniem wielu autorów poprawia wchłanianie witamin, tłuszczów, peptydów i niektórych mikroelementów (Fe, K) oraz utrzymuje prawie fizjologiczne współdziałanie hormonów jelitowych. Może to mieć wpływ na szybszy powrót należnej masy ciała, normalnej aktywności i mniejsze ryzyko powikłań późnych [15]. Istnieją również opinie o braku wczesnych korzyści w porównaniu z metodą Roux-en-Y [16].

Rozpoznanie raka w polipie żołądka jest standardowym wskazaniem do leczenia endoskopowego. Metaanalizy dostępnych badań wskazują na podobne wyniki odległe przy nieco większym odsetku nawrotów i mniejszej radykalności resekcji dla metod endoskopowych w porównaniu z chirurgią. Kryteria radykalnego leczenia metodą endoskopowej mukozektomii obejmują:

- resekcję nowotworu en block,

- wymiar zmiany do $2 \mathrm{~cm}$,

- G1 lub G2,

- pT1a,

- ujemny margines poziomy i pionowy,

- brak limfo- i angioinwazji.

W omawianym przypadku u chorej nie odnaleziono miejsca po nieradykalnej onkologicznie polipektomii i dlatego nie skierowano jej do dalszego leczenia endoskopowego. Dopiero badanie histopatologiczne preparatu operacyjnego potwierdziło rzeczywiste zaawansowanie nowotworu (pT1aN0M0). W tym świetle postępowanie chirurgiczne można byłoby uznać za overtreatment, gdyby nie dobre wczesne wyniki leczenia, w tym dobra jakość życia i dobre rokowanie onkologiczne.

Konflikt interesów: nie zgłoszono

Dr n. med. Grzegorz Celban

Oddział Chirurgii Onkologicznej z Pododdziałem Chorób Piersi Jurajskie Centrum Onkologii

ul. Bialska 104/118, 42-200 Częstochowa

e-mail:gcel@tlen.pl

Otrzymano: 9 stycznia 2016 r.

Przyjęto do druku: 23 lutego 2016 r. 


\section{Piśmiennictwo}

1. Kulig J, Wallner G, Drews M i wsp. Polish consensus on treatment of gastric cancer. Pol Przegl Chir 2013; 85: 544-562.

2. Popiela T, Legutko J. Nowotwory żołądka. W: Jeziorski A, Szawłowski A, TowpikE (red.). Chirurgia onkologiczna. Warszawa:PZWL, 2009: 1034-1071.

3. Aikou T, Natsugoe S, Shimazu H i wsp. Antrum preserving double tract method for reconstruction following proximal gastrectomy. Jpn J Surg 1988; 18: 114-115.

4. Nakamura $\mathrm{M}$, Yamaue $\mathrm{H}$. Reconstruction after proximal gastrectomy for gastric cancer in the upper third of the stomach: a review of the literature published from 2000 to 2014. Surg Today 2016; 46: 517-527.

5. Hong J, Qian L, Wang YP i wsp. A novel method of delta-shaped intracorporeal double-tract reconstruction in totally laparoscopic proximal gastrectomy. Surg Endosc 2015; Sept 28. [Epub ahead of print].

6. Jung do H, Ahn SH, Park do J i wsp. Proximal Gastrectomy for Gastric Cancer. J Gastric Cancer 2015; 15: 77-86.

7. Xiao JW, Liu ZL, Ye PC i wsp. Clinical comparison of antrum-preserving double tract reconstruction vs Roux-en-Y reconstruction after gastrectomy for Siewert types II and III adenocarcinoma of the esophagogastric junction. World J Gastroenterol 2015; 21: 9999-10007.

8. Nomura E, Lee SW, Kawai M i wsp. Functional outcomes by reconstruction technique following laparoscopic proximal gastrectomy for gastric cancer: double tract versus jejunal interposition. World J Surg Oncol 2014; 27: 12-20.
9. Ahn $\mathrm{SH}$, Jung do H, Son SY i wsp. Laparoscopic double-tract proximal gastrectomy for proximal early gastric cancer. Gastric Cancer 2014; 17: $562-570$.

10. Nakajima K, Kawano M, Kinami Si wsp. Dual-radionuclide simultaneous gastric emptying and bile transit study after gastric surgery with double-tract reconstruction. Ann Nucl Med 2005; 19: 185-191.

11. Nomura E, Lee SW, Tokuhara T i wsp. Functional outcomes according to the size of the gastric remnant and type of reconstruction following open and laparoscopic proximal gastrectomy for gastric cancer. Hepatogastroenterology 2012; 59: 1677-1681.

12. Nakane $Y$, Michiura T, Inoue K i wsp. Role of pyloroplasty after proximal gastrectomy for cancer. Hepatogastroenterology 2004; 51: 1867-1871.

13. Namikawa T, Munekage $\mathrm{E}$, Kitagawa $\mathrm{H}$ i wsp. Double tract reconstruction after gastrectomy facilitates endoscopic access to the biliary tree. Dig Dis Sci 2013; 58: 1422-1427.

14. Bandurski R, Gryko M, Kamocki Z i wsp. Double tract reconstruction (DTR) - an alternative type of digestive tract reconstructive procedure after total gastrectomy — own experience. Pol Przeg/Chir 2011;83: 70-75.

15. Kalmar K, Nemeth J, Kelemen D i wsp. Postprandial gastrointestinal hormone production is different, depending on the type of reconstruction following total gastrectomy. Ann Surg 2006; 243: 465-471.

16. Iwahashi M, Nakamori M, Nakamura M i wsp. Evaluation of double tract reconstruction after total gastrectomy with gastric cancer: prospective randomized controlled trial. World J Surg 2009; 33: 1882-1888. 